\title{
Article \\ Adaptive Harmony Search for Tuned Liquid Damper Optimization under Seismic Excitation
}

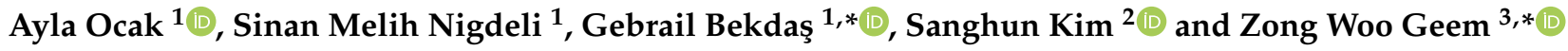 \\ 1 Department of Civil Engineering, University-Cerrahpaşa, 34320 Istanbul, Turkey; \\ aylaocak@outlook.com (A.O.); melihnig@iuc.edu.tr (S.M.N.) \\ 2 Department of Civil and Environmental Engineering, Temple University, Philadelphia, PA 19122, USA; \\ sanghun.kim@temple.edu \\ 3 College of IT Convergence, Gachon University, Seongnam 13120, Korea \\ * Correspondence: bekdas@iuc.edu.tr (G.B.); geem@gachon.ac.kr (Z.W.G.)
}

check for updates

Citation: Ocak, A.; Nigdeli, S.M.; Bekdaş, G.; Kim, S.; Geem, Z.W. Adaptive Harmony Search for Tuned Liquid Damper Optimization under Seismic Excitation. Appl. Sci. 2022, 12 2645. https://doi.org/10.3390/ app12052645

Academic Editor: Alberto Benato

Received: 3 February 2022

Accepted: 1 March 2022

Published: 3 March 2022

Publisher's Note: MDPI stays neutral with regard to jurisdictional claims in published maps and institutional affiliations.

Copyright: (C) 2022 by the authors. Licensee MDPI, Basel, Switzerland. This article is an open access article distributed under the terms and conditions of the Creative Commons Attribution (CC BY) license (https:// creativecommons.org/licenses/by/ $4.0 /)$

\begin{abstract}
In this study, the tuned liquid damper (TLD) device was optimized by the harmony search (HS) and adaptive harmony search algorithms (AHS). Using the harmony search algorithm, seismic excitations were directed at single and ten-story structures, and TLD parameters were optimized to minimize building movement. To improve design parameters, the optimization process was repeated by adapting the design factors of the harmony search algorithm. For this purpose, both the harmony memory consideration ratio (HMCR) and fret width (FW) were gradually reduced by providing an initial value, and optimum algorithm parameters were obtained. As a result of both optimizations, in a critical seismic analysis, the displacements of the adaptive harmony search showed smaller means and standard deviations than those of the classical harmony search.
\end{abstract}

Keywords: harmony search; adaptive harmony search; tuned liquid damper; structural control; optimization

\section{Introduction}

Passive dampers are the preferred systems for vibration control of structures because of their low cost, ability to be added to existing buildings, and ease of maintenance and repair. A tuned liquid damper (TLD) is a passive control device that absorbs the movement of the building without any external energy. It has sloshing energy provided by the viscosity and density of the liquid it contains. In terms of basic operating principles, it is similar to tuned mass dampers (TMD), which consist of a spring and mass model. A TLD aims to minimize damage to the structure caused by dynamic effects by connecting the structure with spring and liquid mass. The type of fluid chosen for damping affects the damping performance significantly. The density of the liquid, or its kinematic viscosity, affects the damping performance, and, thus, the sloshing. When evaluated in terms of the characteristic features of the design of TLDs, there are studies in which the use of water, and mixtures including water, as the liquid, has shown good results in terms of performance in various vibration control, easy accessibility, and cost [1,2]. Another feature that affects damping is the geometrical characteristics of the damper tank. TLD tanks can be designed in rectangular prism, cylindrical, or conical shapes. The effects of tank shapes on vibration control have been investigated in various studies. It has been determined that they have remarkable effects on damping. Chang and $\mathrm{Gu}$ found that rectangular-based TLDs have remarkable effects in preventing eddy vibrations in their study [3]. Casciati et al. showed that the truncated conical TLD tank model can be an alternative to the cylindrical TLD tank [4]. Love and Tait worked on the constraints of the rectangular shape in tank designs and developed a TLD tank design method [5]. Zhang took tank geometry in another direction with his research, and observed that curved-bottom TLDs could be better than flat-bottom TLDs, with less liquid [6]. Cavalagli et al. conducted an experimental study 
with round, rectangular, and inclined TLD tanks, and concluded that the inclined tank can provide more efficient results, but is less durable [7]. Effective liquid length and tank height are the main parameters in the damping effect of the tank geometry. The effective liquid length is the base size, which denotes the long side, where agitation is easily directed. Fujino et al. (1992) suggested a ratio between this length and the tank height in a study [8]. Another parameter that affects TLD performance is mass. The recommended $5 \%$ mass ratio for TMDs can be applied to TLDs as well, and it is recommended in the literature that TLD mass should be between $1 \%$ and $4 \%$ [9-12].

The importance of the design parameters of TLDs in vibration control has necessitated the optimization process. For this purpose, optimization is carried out using various algorithms. Metaheuristic algorithms take their inspiration from spontaneous events in nature, and the instinctive behavior of living things. These algorithms transform a mathematical model of the instinctive behavior of living things, such as the magnificent order in the flight of the birds, the path of the bees to their colony in search of food, bats' detection of objects by echolocation, or the bubble road map created by humpback whales while hunting, into a metaheuristic algorithm, and ensure that the best solutions are obtained. The minimum energy that living things expend to survive, processed by order based on maximum gain, in the algorithms, makes optimum efficiency possible. The systematic order in mathematical models distinguishes metaheuristic algorithms from other optimization algorithms. The harmony search algorithm (HS) is a type of metaheuristic algorithm developed by Geem et al. [13]. This algorithm, which aims to achieve the best harmony, can search for a favorite harmony in the memory bank during the search process, create a melody similar to this harmony, or improvise for optimum harmony by creating an unheard harmony from scratch [14]. The effect of the harmony search algorithm on design optimization has been supported by various studies [15-21]. In recent years, it has become a preferred algorithm in damper optimization by being applied in the design of mass and liquid dampers [2,22,23]. The harmony search algorithm includes design factors such as memory consideration ratio (HMCR) and fret width (FW). The correct selection of these algorithm-specific factors is of great importance for the efficiency of the optimization. It is possible to start a progressively decreasing search process within a certain range by giving initial values to the HMCR and FW parameters. This process has developed the adaptive harmony search algorithm (AHS). Optimizing the design factors makes the algorithm more efficient. Thanks to the adjustments made to the parameters of the classical HS algorithm, positive results were obtained in the design optimization of engineering structures. Zhang and Zhang used the improved harmony search algorithm (IHS), produced by adjusting the fret width (FW) and bandwidth (BW) of the HS algorithm, in the optimization of mass dampers used in the design of a water intake tower. IHS provided optimum frequency, damping, and mass ratio calculations, and obtained better results than the optimization method of Den Hartog, Warburton, Sadek, et al., Leung, and Zhang [24-28]. In engineering, optimization of tuned mass dampers, steel-framed structures, nonlinear plane strain systems, reinforced concrete shear walls, etc., are studied with the optimization of AHS and its hybrids. The classical HS algorithm, with adaptation of algorithm parameters, showed better results than some metaheuristic algorithms [29-33]. Since the HS algorithm has been successfully applied to many structural engineering problems, including control applications, it has been recently proven that the performance of the algorithm can be increased by improving the algorithm with adaptive methods; adaptive HS has been applied in TLDs, which are a different passive structural control problem. The best knowledge of this algorithm is another reason for choosing this algorithm.

In this study, by adding a cylindrical TLD to single and ten-story building models, the damper parameters were optimized with the HS algorithm to obtain the minimum displacement under seismic excitation. A TLD based on water was applied to both singlestory structures with a natural period of $0.5 \mathrm{~s}, 1 \mathrm{~s}$, and $1.5 \mathrm{~s}$, and a ten-story structure. Optimization was obtained by applying various seismic excitations using a simulation prepared on MATLAB [34,35]. The classical HS algorithm parameters were adjusted, the 
optimization process was repeated with the AHS algorithm, and the results of the two algorithms were analyzed for critical earthquake recording. In light of the results obtained, the classical HS and adapted AHS algorithms were compared. For a single case study, two other modified HS algorithms were also compared to show the efficiency of the AHS.

\section{Materials and Methods}

\subsection{Design of TLDs and Equations of Motion}

In practice, many TLDs have been included in structures. The British Airways i360 tower is shown as an example (Figure 1). Other examples include the Nagasaki Airport Tower, Tokyo Sofitel Hotel, Yokohoma Marine Tower, Shin Yokohoma Prince Hotel, Sakitama Bridge, Narita Airport Control Tower, and Emley Moor Tower.

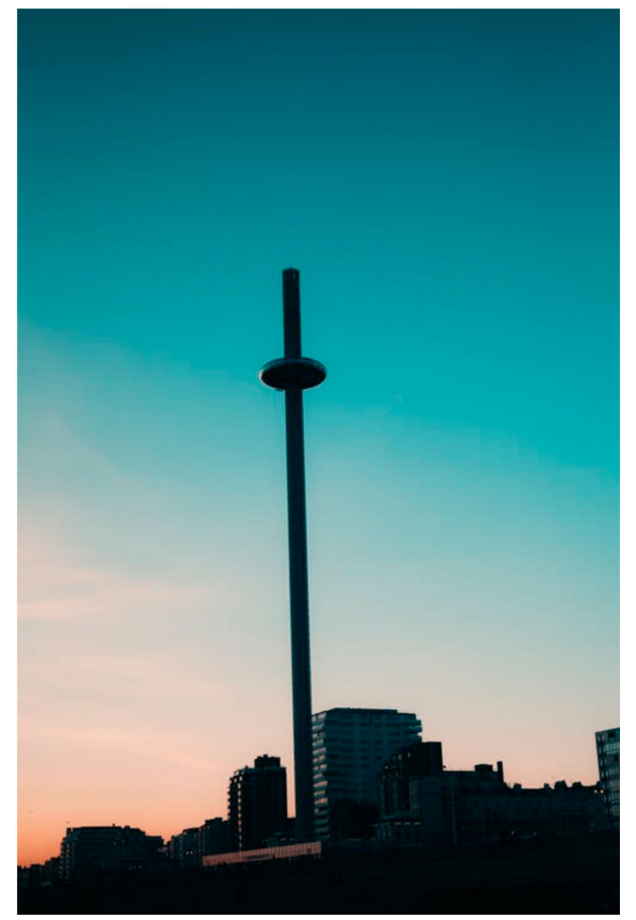

Figure 1. The British Airways i360 tower.

While designing tuned liquid dampers, the most important design variables are the geometrical characteristics of the tank, its mass, the damper period, and the damping ratio. The effect of tank geometry on sloshing has been demonstrated by various studies, and a design ratio $\left(\frac{h}{2 R}>0.15\right)$ between tank height and effective liquid length has been proposed [8]. The recommended 5\% mass ratio for mass dampers is also used as a suitable ratio for liquid dampers. The selection of the damper period is another factor that should be considered in terms of the performance of the TLD. Since the tank period expresses the circulation time of the liquid in the system, it directly affects the sloshing, and thus, the damping. These parameters, which are interconnected, form the basic motion equations of the system.

In this study, a regulated liquid damper with a cylindrical tank was used. In Figure 2a, a $3 \mathrm{D}$ scheme of the building plus the TLD is shown. This scheme is also provided as a 2D figure, in Figure $2 b$, that shows the dimensions and parameters of the TLD. Finally, an idealized figure representing the single-story structure model plus the TLD is provided in Figure 2c. 


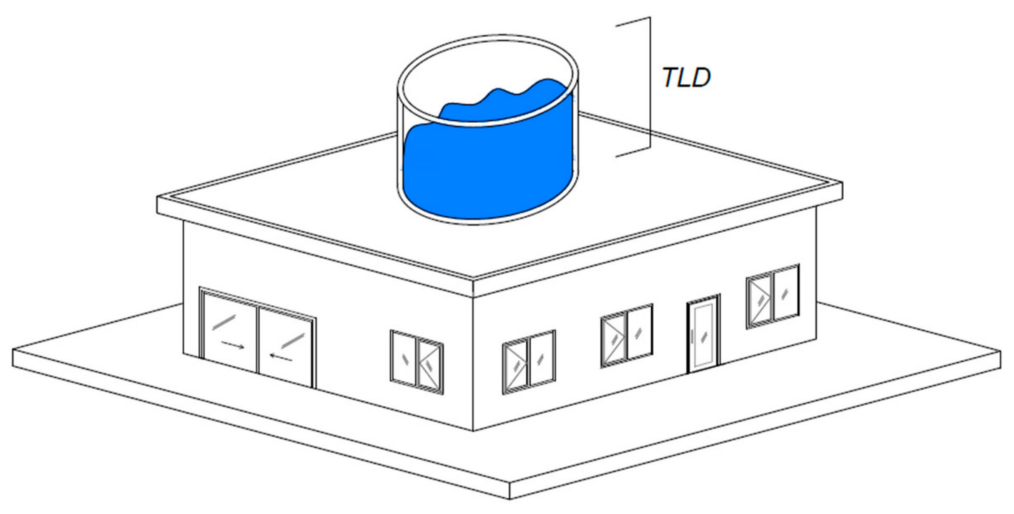

(a)

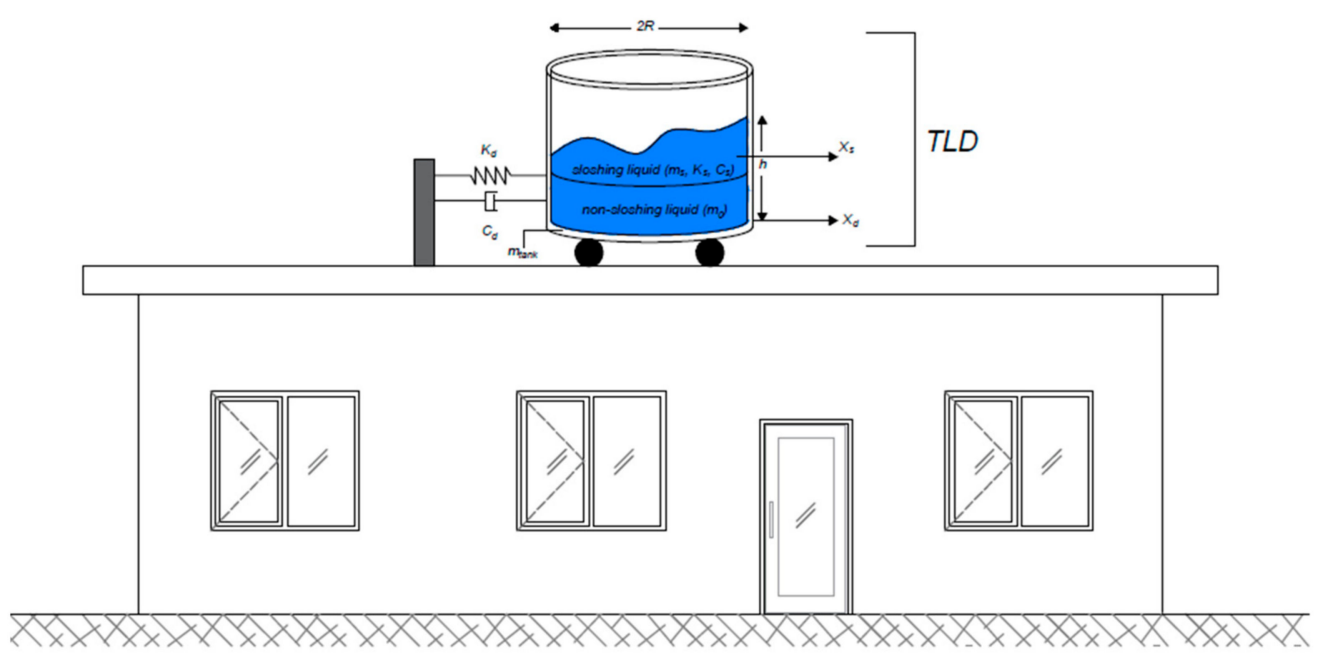

(b)
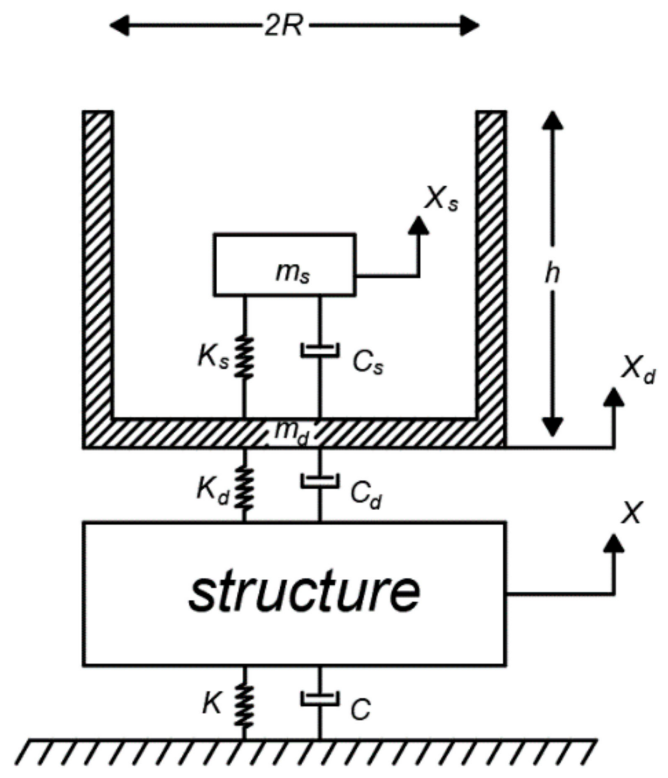

(c)

Figure 2. Structure plus TLD models: (a) 3D; (b) 2D; (c) Idealised model. 
The information used in the creation of the equations of motion of the cylindrical TLD device is provided below.

The TLD mass ratio $(\mu)$ is shown in Equation (1). Here, $m$ denotes the mass of the structure and $m_{T L D}$ denotes the mass of the damper.

$$
\mu=\frac{m_{T L D}}{m}
$$

It is known that, in the basic liquid sloshing principle, liquids are not completely shaken, and some liquids remain passive and are not included in the sloshing. The passive liquid that remains dormant in the TLD and the active liquid that is sloshing should be considered separately. Together with the passive liquid TLD tank, this acts as a two-degreeof-freedom system independent of the active liquid tank. Equations (2) and (3) show the calculation of the mass of the sloshing liquid and passive liquid plus the empty tank. Here, $m_{s}$ is the sloshing liquid, $m_{s t}$ is the total liquid, $m_{T L D}$ is the TLD mass, and $m_{d}$ is the mass of the empty tank plus the mass of the passive liquid. The radius and height of the cylindrical tank are indicated by $h$ and $R$.

$$
\begin{gathered}
m_{s}=m_{s t} \times R \times \frac{\tanh \left(\frac{1.84 h}{R}\right)}{2.2 h} \\
m_{d}=m_{m_{T L D}}-m_{s}
\end{gathered}
$$

The Bessel function is a function used in solving problems related to the wave propagation of cylindrical bodies. The roots of this function form the damping rate parameter $(\xi \mathrm{mn})$, which specifies the indices of vibration modes in the tangential (m) and radial (n) directions [36]. Damping rate parameter was found to be 1.84 in the first vibration mode in the tangential and radial directions, which accounted for the fundamental mode of the liquid [36,37]. With the help of this value, the natural frequency of the sloshing liquid can be calculated, as well as the lateral force acting on the walls of the tank, calculated according to the linearized hydrodynamic theory of sloshing [36,38]. In this way, the sloshing liquid mass (Equation (2)) and sloshing liquid stiffness are derived.

Equations (4) and (5) show the TLD stiffness $\left(k_{d}\right)$ and sloshing fluid stiffness $\left(k_{s}\right)$ calculations, while Equations (6) and (7) show the TLD damping coefficient $\left(c_{d}\right)$ and sloshing fluid damping coefficient $\left(c_{S}\right)$ calculations. The damper period is expressed as $T_{d}$. The damping ration of the sloshing liquid was obtained from experimental study data in the literature $[36,39,40]$. g represents gravity. $\zeta_{s}$ is formulated as in Equation (8). The kinematic viscosity of the fluid is shown as $v$.

$$
\begin{gathered}
k_{d}=m_{d} \times\left(\frac{2 \pi}{T_{d}}\right)^{2} \\
k_{s}=m_{s t} \times \frac{g\left\{\tanh \left(\frac{1.84 h}{R}\right)\right\}^{2}}{1.19 h} \\
c_{d}=2 \times \zeta_{d} \times \sqrt{m_{d} \times k_{d}} \\
c_{s}=\zeta_{s} \times 2 \sqrt{m_{s} k_{s}} \\
\zeta_{s}=4.98 v^{\frac{1}{2}} R^{-\frac{3}{4}} g^{-\frac{1}{4}}\left[1+\frac{0.318}{\sinh \left(\frac{1.84 h}{R}\right)} \frac{1-\frac{h}{R}}{\cosh \left(\frac{1.84 h}{R}\right)}\right]
\end{gathered}
$$

In Equation (9), the damping ratio calculation of the damper is shown. The damping ratio is denoted by $\zeta_{d}$.

$$
\zeta_{d}=\frac{c_{d}}{2 m_{d} \sqrt{\frac{k_{d}}{m_{d}}}}
$$


The mass, stiffness, and damping coefficient matrices of the structure plus TLD model are shown in Equations (10)-(12), respectively, and the basic equation of motion is provided in Equation (13). In the equations, terms with the " $s$ " index belong to the sloshing liquid, those with the " $d$ " index belong to TLD, and terms without an index belong to the structure.

$$
\begin{aligned}
& {\left[\begin{array}{ccc}
m & 0 & 0 \\
0 & m_{d} & 0 \\
0 & 0 & m_{s}
\end{array}\right]} \\
& {\left[\begin{array}{ccc}
K+K_{d} & -K_{d} & 0 \\
-K_{d} & K_{d}+K_{s} & -K_{s} \\
0 & -K_{s} & K_{s}
\end{array}\right]} \\
& {\left[\begin{array}{ccc}
C+C_{d} & -C_{d} & 0 \\
-C_{d} & C_{d}+C_{s} & -C_{s} \\
0 & -C_{s} & C_{s}
\end{array}\right]} \\
& {[M]\{\ddot{X}\}+[C]\{\dot{X}\}+[K]\{X\}=-[M] 1\left\{\ddot{X}_{g}\right\}}
\end{aligned}
$$

\subsection{Harmony Search and Adaptive Harmony Search Algorithm}

The harmony search algorithm is a metaheuristic algorithm inspired by the best harmony search process developed by Geem et al. Memory consideration, used in classical HS, was eliminated to adapt the problem optimization, to increase the convergence capacity. In this case, a parameter called pitch adjusting rate (PAR) was not used, and the formulations of HS were simplified. In addition, the adaptive version of HS was used to actively change two parameters of HS. Due to the use of adaptive parameters and the elimination of PAR, the algorithm used in this study is less parameter-dependent than the classical version. In the algorithm operation, design limit values, iteration number, algorithm-specific harmony memory consideration rate (HMCR), fret width (FW), and harmony memory size (HMS) were defined. A random number between 0 and 1 is shown as rand. In AHS, the initial values for the parameters were defined. These initial parameters $\left(X_{\text {initial }}\right)$ were defined according to Equation (14) by using the whole solution range. The maximum and minimum ranges of design variables are shown as $X_{\min }$ and $X_{\max }$, respectively.

$$
X_{\text {initial }}=X_{\text {min }}+\operatorname{rand}\left(X_{\max }-X_{\min }\right) \text { for } \mathrm{T}_{\mathrm{d}}, \zeta_{\mathrm{d}}, \mathrm{R} \text { and } \mathrm{h}
$$

$X_{n e w}$ defines a candidate value of a design variable. Then, a harmony is memorized. A new harmony vector is generated, as shown in Equation (15) or (16), keeping the design within the lower and upper limit values. The results obtained by writing the harmony vector values in the objective function are stored in the memory. This process is repeated for the amount of HMS, and each harmony vector created is stored in a solution matrix.

$$
X_{\text {new }}=X_{\text {min }}+\text { rand }\left(X_{\text {max }}-X_{\text {min }}\right) \text { if } H M C R>\text { rand }
$$

Another way to obtain the harmony vector is calculations based on the FW value, as shown in Equation (15). An existing candidate solution is chosen and is shown as $X_{n}$. Which equation will be used to create the harmony vector is decided by the HMCR value. If a randomly selected value between zero and one is less than HMCR, Equation (14) is chosen. If it is larger, Equation (15) is selected to create a new harmony vector.

$$
X_{\text {new }}=X_{n}+\text { rand } \mathrm{FW}\left(X_{\max }-X_{\text {min }}\right) \text { if } H M C R \leq \text { rand }
$$

The design variables of the TLD optimization problem are $T_{d}, \zeta_{d}, R$, and $h$. After assigning candidate values to these variables, the mass, stiffness, and damping coefficient values of the TLD can be calculated via the formulations presented in Section 2.1. Then, the 
coupled equation of motion, Equation (13), can be solved via dynamic analysis performed with MATLAB and Simulink [35].

The newly created harmony vectors are compared with the previously stored old harmony vectors. If the new solutions are better than the old solution, the old solutions are updated; otherwise, the old solution remains as it is. These operations are repeated for the amount of iteration by controlling the boundary conditions, and the solution vector takes its final form. The objective function $(f(X))$ is the minimization of maximum top story displacement (dis $(\mathrm{tm}))$ that occurs as maximum for various earthquake records in time (tm) domain analyses. It is formulated as Equation (17).

$$
f(X)=\operatorname{minimize}(\max (|\operatorname{dis}(t m)|))
$$

To obtain the adaptive harmony search algorithm, an initial value is assigned to the classical HS algorithm parameters (HMCR and FW), and these values are written in decreasing order. Thus, the optimum solution is sought for all values, from the initial value to the smallest value. Equations (18) and (19) show the HMCR and FW calculations.

$$
\begin{gathered}
H M C R=H M C R_{\text {in }}\left(1-\frac{t}{m t}\right) \\
F W=F W_{\text {in }}\left(1-\frac{t}{m t}\right)
\end{gathered}
$$

Here, the $H M C R_{\text {in }}$ and $F W_{\text {in }}$ values represent the initial values of the algorithm parameter. In the equations, $t$ represents the iteration number and $m t$ represents the maximum number of iterations.

\section{Numerical Examples}

In this study, a model was created by placing a water-based TLD device based on single-story and ten-story structures. Twenty-two earthquake records, defined as far-field records in FEMA P-695 [34], were directed in simulations. The list of FEMA earthquake records applied to single and ten-story structure models are provided in Table 1.

Table 1. FEMA earthquake records list.

\begin{tabular}{ccccc}
\hline $\begin{array}{c}\text { Earthquake } \\
\text { Number }\end{array}$ & Date & Earthquake Name & Component 1 & Component 2 \\
\hline 1 & 1994 & Northridge & NORTHR/MUL009 & NORTHR/MUL279 \\
2 & 1994 & Northridge & NORTHR/LOS000 & NORTHR/LA270 \\
3 & 1999 & Duzce, Turkey & DUZCE/BOL0000 & DUZCE/BOL090 \\
4 & 1999 & Hector Mine & HECTOR/HEC000 & HECTOR/HEC090 \\
5 & 1979 & Imperial Valley & IMPVALL/H-DLT262 & IMPVALL/H-DLT352 \\
6 & 1979 & Imperial Valley & IMPVALL/H-E11140 & IMPVALL/H-E11230 \\
7 & 1995 & Kobe, Japan & KOBE/NIS000 & KOBE/NIS090 \\
8 & 1995 & Kobe, Japan & KOBE/SHI000 & KOBE/SHI090 \\
9 & 1999 & Kocaeli, Turkey & KOCAELI/DZC180 & KOCAELI/DZC270 \\
10 & 1999 & Kocaeli, Turkey & KOCAELI/ARC000 & KOCAELI/ARC090 \\
11 & 1992 & Landers & LANDERS/PLACE270 & LANDERS/YER360 \\
12 & 1992 & Landers & LANDERS/CLW-LN & LANDERS/CLW-TR \\
13 & 1989 & Loma Prieta & LOMAP/CAP000 & LOMAP/CAP090 \\
14 & 1989 & Loma Prieta & LOMAP/G03000 & LOMAP/G03090 \\
15 & 1990 & Manjil, Iran & MANJIL/ABBAR-L & MANJIL/ABBAR-T \\
16 & 1987 & Superstition Hills & SUPERST/B-ICC000 & SUPERST/B-ICC090 \\
17 & 1987 & Superstition Hills & SUPERST/B-POE270 & SUPERST/B-POE360 \\
18 & 1992 & Cape Mendocino & CAPEMEND/RIO270 & CAPEMEND/RIO360 \\
19 & 1999 & Chi-Chi, Taiwan & CHICHI/CHY101-E & CHICHI/CHY101-N \\
20 & 1999 & Chi-Chi, Taiwan & CHICHI/TCU045-E & CHICHI/TCU045-N \\
21 & 1971 & San Fernando & SFERN/PEL090 & SFERN/PEL180 \\
22 & 1976 & Friuli, Italy & FRIULI/A-TMZ000 & FRIULI/A-TMZ270 \\
\hline
\end{tabular}


The cylindrical tank geometry used in the model was optimized, considering a mass ratio of $5 \%$. The TLD tank radius and height were optimized between $0.1 \mathrm{~m}$ and $10 \mathrm{~m}$, with a damper period of 0.5 to 1.5 times the uncontrolled structure period, and a damping ratio between $1 \%$ and $50 \%$.

In the optimization process on MATLAB, the number of iterations was 1000 , and the pn value was 10. Algorithm parameters are shown in Table 2.

Table 2. The algorithm parameters.

\begin{tabular}{ccc}
\hline Symbol & Definition & Value \\
\hline$H M C R$ & Harmony Memory & $0-0.5$ \\
$H M C R_{i n}$ & Considering Rate & \\
$F W$ & Initial Harmony Memory & 0.5 \\
$F W_{i n}$ & Considering Rate & $0-0.05$ \\
$m t$ & Fret Width & 0.05 \\
$t$ & Initial Fret Width & 1000 \\
$p n$ & Maximum iteration number & $1-1000$ \\
\hline
\end{tabular}

\subsection{Single-Story Structures}

By selecting a mass of 100t for all single-story structures, a three-degrees-of-freedom (3DOF) model was created with the sloshing liquid, the structure, and the TLD plus nonsloshing liquid moving together. The stiffness values obtained were $15.8 \mathrm{MN} / \mathrm{m}, 3.95 \mathrm{MN} / \mathrm{m}$, and $1.75 \mathrm{MN} / \mathrm{m}$, respectively, and the damping coefficients were $0.13 \mathrm{MN} \mathrm{s} / \mathrm{m}, 0.06 \mathrm{MN} \mathrm{s} / \mathrm{m}$, and $0.04 \mathrm{MN} \mathrm{s} / \mathrm{m}$, respectively; the structure period values were between $0.5 \mathrm{~s}$ and $1.5 \mathrm{~s}$. The TLD was optimized to withstand structure period values between 0.5 and 1.5.

After the height and radius values of the cylindrical TLD tank were added to the singlestory structure model, the TLD period and damping ratio were optimized. The results obtained from optimization with the classical harmony search algorithm (HS), adaptive harmony search algorithms (AHS), and two improved harmony search algorithms (IHS [24] and a modified variant of HS (LHS) [41]) are shown in Table 3, for the structure with a $1 \mathrm{~s}$ period.

Table 3. Optimum results for TLD-Water plus single-story structure model ( $\mathrm{T}=1.0 \mathrm{~s})$.

\begin{tabular}{ccccc}
\hline \multirow{2}{*}{ Variables } & \multicolumn{4}{c}{ Optimized Values } \\
\cline { 2 - 5 } & HS & IHS & LHS & AHS \\
\hline$T_{d}(\mathrm{~s})$ & 1.0398 & 1.0291 & 1.0072 & 1.0597 \\
$\zeta_{d}$ & 0.2329 & 0.2217 & 0.2062 & 0.2077 \\
$R(\mathrm{~m})$ & 0.3938 & 0.3074 & 0.2929 & 0.2165 \\
$h(\mathrm{~m})$ & 0.8160 & 6.3230 & 6.1140 & 8.2789 \\
\hline
\end{tabular}

Maximum displacement and total acceleration values were calculated as a result of the analysis performed under FEMA earthquake warnings, with TLD parameters optimized for the $1 \mathrm{~s}$ period of the structure. Table 4 shows the values obtained from the critical earthquake analysis. A critical earthquake record for a single-story structure was recorded in 1999 in Duzce (BOL090) for the $1 \mathrm{~s}$ period. Based on the results, AHS is the best method for minimization of the objective function, taken as displacement of the top story. After the verification of AHS as the best modified algorithm, the other optimization cases were performed for only AHS and classical HS.

HS and AHS optimized values are shown in Table 5 for single-story models with structure periods of $0.5 \mathrm{~s}$ and $1.5 \mathrm{~s}$. For the $0.5 \mathrm{~s}$ and $1.5 \mathrm{~s}$ structure period, the critical earthquake records were 1994 Northridge (MUL279) and 1999 Kocaeli (DZC270) earthquakes, respectively. Tables 6 and 7 show the maximum displacement and total acceleration values obtained from the critical earthquake analysis at the $0.5 \mathrm{~s}$ and $1.5 \mathrm{~s}$ structural periods. 
Table 4. TLD plus single-story building model; critical earthquake analysis results ( $\mathrm{T}=1.0 \mathrm{~s})$.

\begin{tabular}{cccccc}
\hline \multirow{2}{*}{ Algorithm } & \multirow{2}{*}{ Without TLD } & \multicolumn{4}{c}{ Structure with TLD } \\
\cline { 3 - 6 } & & HS & IHS & LHS & AHS \\
\hline Displacement $(\mathrm{m})$ & 0.2873419 & 0.2473086 & 0.2460654 & 0.2450165 & 0.2446071 \\
\cline { 5 - 6 } Total Acceleration $\left(\mathrm{m} / \mathrm{s}^{2}\right)$ & 11.4077630 & 9.6358656 & 9.5542167 & 9.4776471 & 9.5648807 \\
\hline
\end{tabular}

Table 5. Optimum results for TLD-water plus single-story structure model ( $\mathrm{T}=0.5 \mathrm{~s}$ and $\mathrm{T}=1.5 \mathrm{~s}$ ).

\begin{tabular}{|c|c|c|c|c|}
\hline \multirow{3}{*}{ Variables } & \multicolumn{4}{|c|}{ Optimized Values } \\
\hline & \multicolumn{2}{|c|}{$\mathrm{T}=0.5 \mathrm{~s}$} & \multicolumn{2}{|c|}{$\mathrm{T}=1.5 \mathrm{~s}$} \\
\hline & HS & AHS & HS & AHS \\
\hline$T_{d}(\mathrm{~s})$ & 0.6555 & 0.6519 & 1.3721 & 1.3873 \\
\hline$\zeta_{d}$ & 0.2189 & 0.2182 & 0.1795 & 0.1705 \\
\hline$R(\mathrm{~m})$ & 0.2341 & 0.2214 & 0.7725 & 0.7636 \\
\hline$h(\mathrm{~m})$ & 5.8274 & 1.5643 & 1.4396 & 1.6813 \\
\hline
\end{tabular}

Table 6. TLD plus single-story building model; critical earthquake analysis results $(T=0.5 \mathrm{~s})$.

\begin{tabular}{|c|c|c|c|}
\hline \multirow{2}{*}{ Algorithm } & \multirow{2}{*}{$\begin{array}{c}\text { Structure } \\
\text { Without TLD }\end{array}$} & \multicolumn{2}{|c|}{ Structure with TLD } \\
\hline & & HS & AHS \\
\hline Displacement (m) & 0.1774455 & 0.1273578 & 0.1268410 \\
\hline Total Acceleration $\left(\mathrm{m} / \mathrm{s}^{2}\right)$ & 28.0477691 & 20.4824088 & 20.3932509 \\
\hline
\end{tabular}

Table 7. TLD plus single-story building model; critical earthquake analysis results $(T=1.5 \mathrm{~s})$.

\begin{tabular}{cccc}
\hline Algorithm & Structure & & \multicolumn{2}{c}{ Structure with TLD } \\
\cline { 3 - 5 } & Without TLD & HS & AHS \\
\hline Displacement $(\mathrm{m})$ & 0.2927541 & 0.2574074 & 0.2567679 \\
\hline Total Acceleration $\left(\mathrm{m} / \mathrm{s}^{2}\right)$ & 5.2223281 & 4.5565000 & 4.5520700 \\
\hline
\end{tabular}

The displacement-time and total acceleration-time graphs obtained from the critical seismic analysis, as a result of HS optimization, are shown in Figures 3-5 for $0.5 \mathrm{~s}, 1.0 \mathrm{~s}$, and $1.5 \mathrm{~s}$, respectively, and in Figures 6-8 for AHS optimization in a single-story structure.
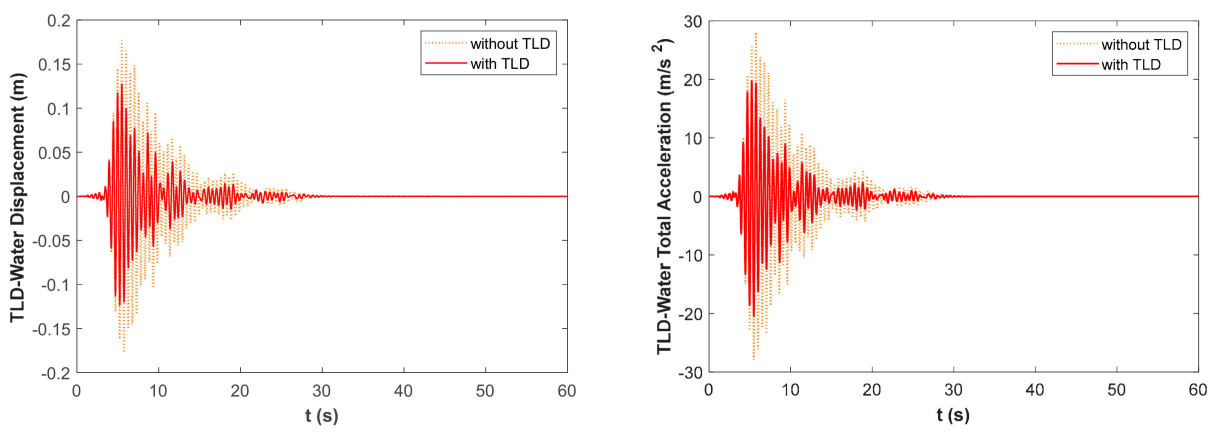

Figure 3. HS optimization, displacement-time, and total acceleration-time graphs of critical seismic analysis in a single-story structure $(\mathrm{T}=0.5 \mathrm{~s})$. 

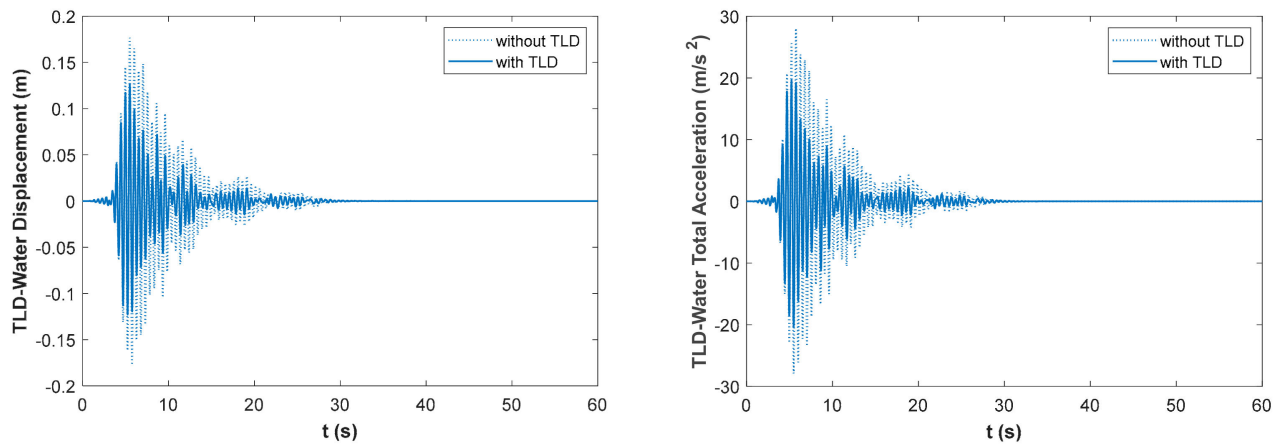

Figure 4. AHS optimization, displacement-time, and total acceleration-time graphs of critical seismic analysis in a single-story structure $(\mathrm{T}=0.5 \mathrm{~s})$.
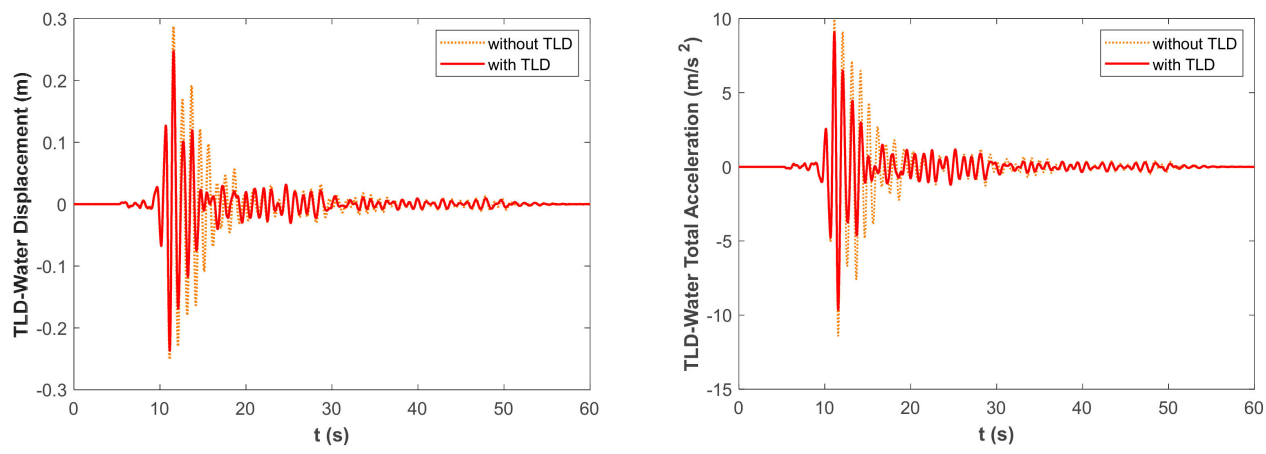

Figure 5. HS optimization, displacement-time, and total acceleration-time graphs of critical seismic analysis in a single-story structure $(\mathrm{T}=1.0 \mathrm{~s})$.
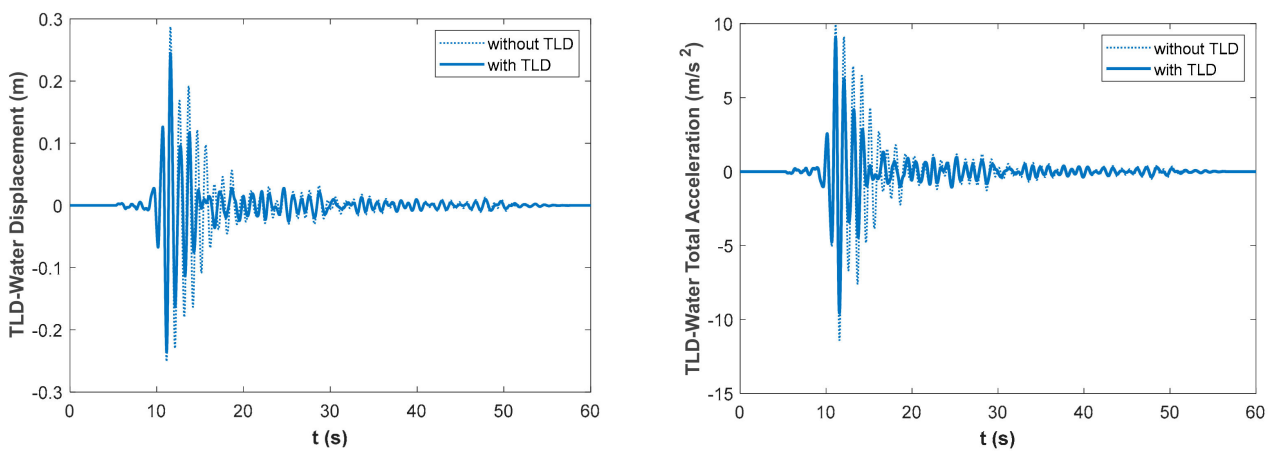

Figure 6. AHS optimization, displacement-time, and total acceleration-time graphs of critical seismic analysis in a single-story structure $(\mathrm{T}=1.0 \mathrm{~s})$.
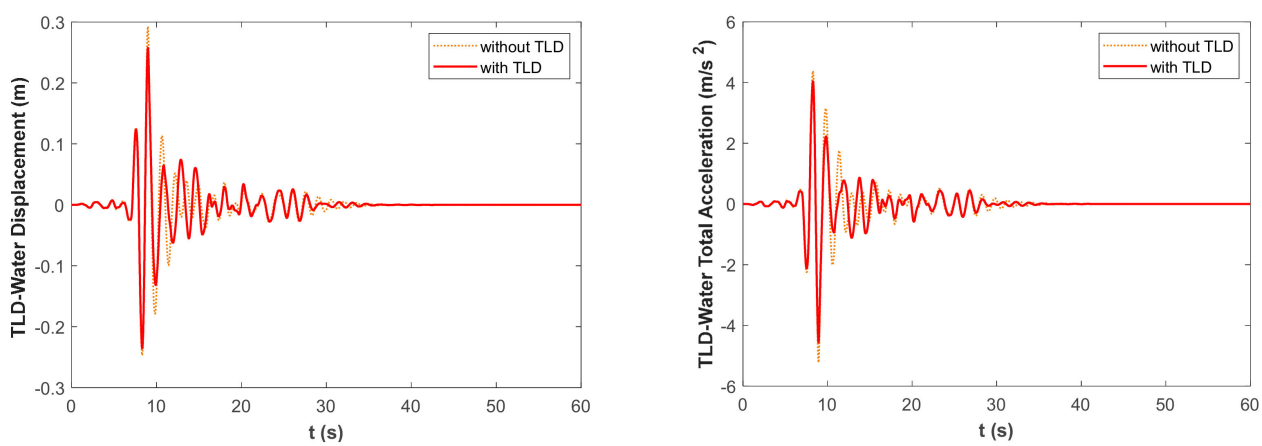

Figure 7. HS optimization, displacement-time, and total acceleration-time graphs of critical seismic analysis in a single-story structure $(T=1.5 \mathrm{~s})$. 

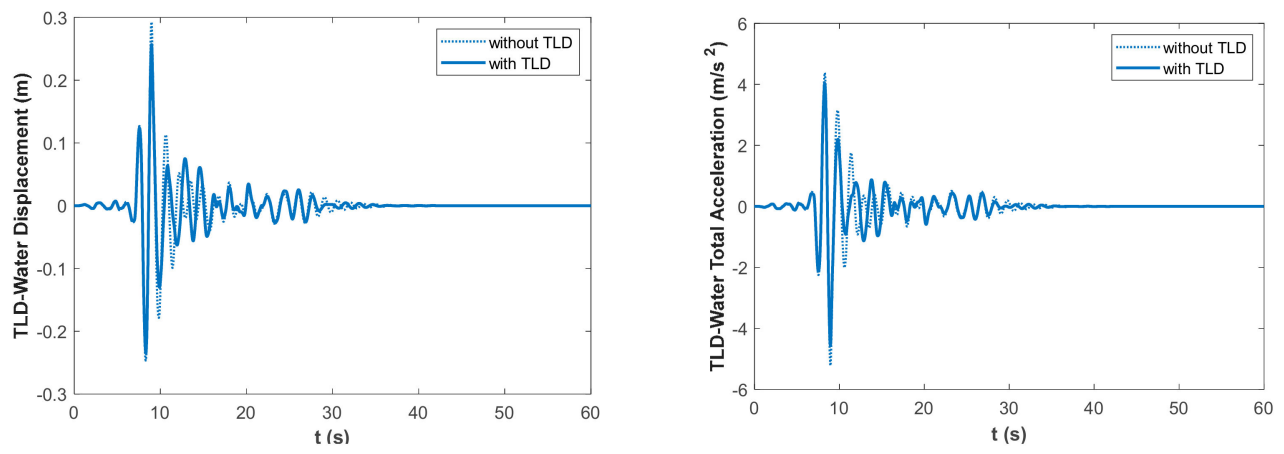

Figure 8. AHS optimization, displacement-time, and total acceleration-time graphs of critical seismic analysis in a single-story structure $(\mathrm{T}=1.5 \mathrm{~s})$.

\subsection{Ten-Story Structure}

The ten-story structure had the same mass (360 t), damping coefficient $(6.2 \mathrm{MN} \mathrm{s} / \mathrm{m})$, and stiffness $(650 \mathrm{MN} / \mathrm{m})$ for all stories [42]. The twelve-degree-of-freedom system (12DOF) model, created by adding values together over the ten-story structure, is shown in Figure 9. Optimum TLD parameters, obtained by optimization of the HS and AHS algorithms, are shown in Table 8 for the ten-story structure.

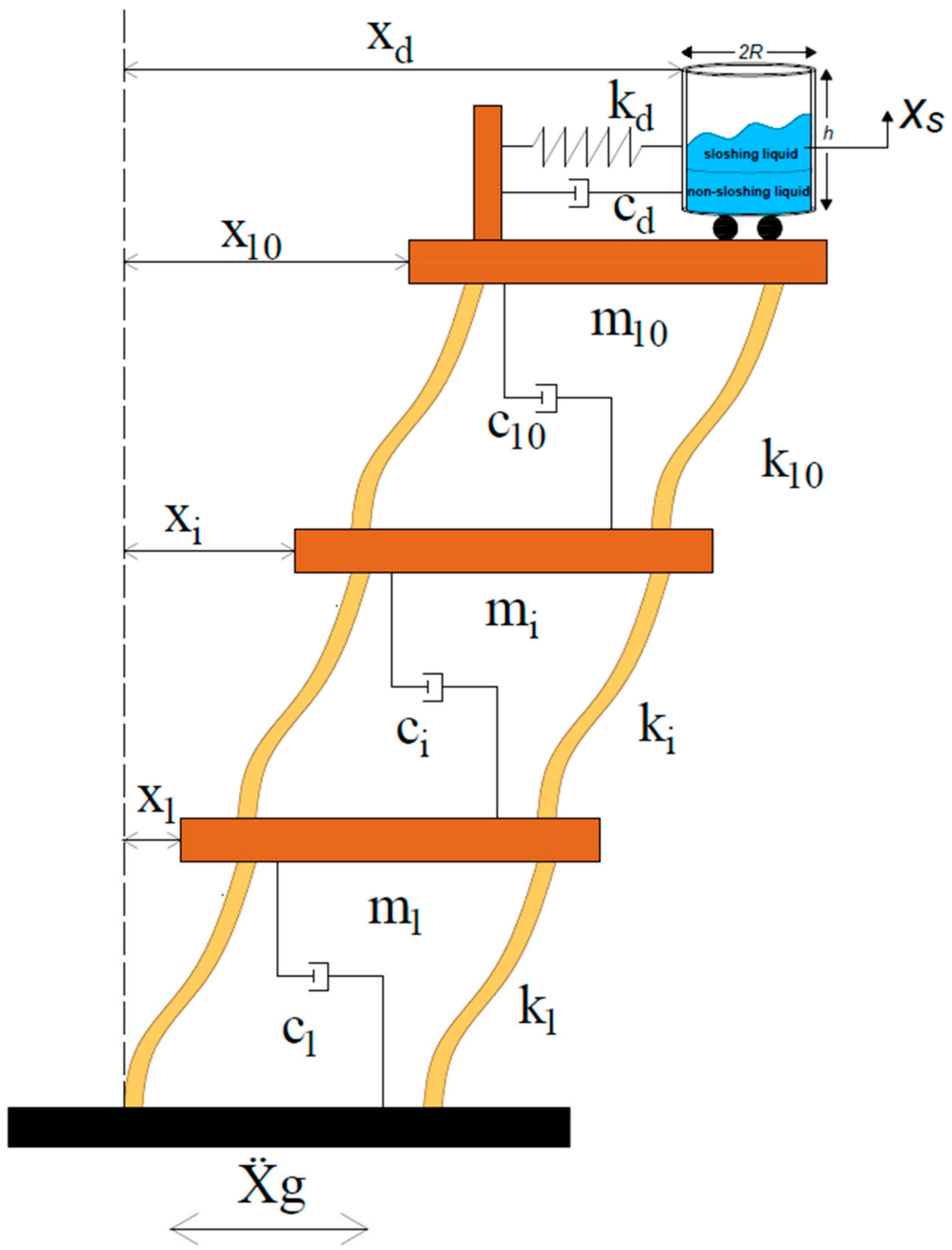

Figure 9. TLD plus ten-story structure model. 
Table 8. Optimum results for TLD-water plus ten-story structure model.

\begin{tabular}{ccc}
\hline \multirow{2}{*}{ Variables } & \multicolumn{3}{c}{ Optimized Values } \\
\cline { 2 - 3 } & HS & AHS \\
\hline$T_{d}(\mathrm{~s})$ & 0.9956 & 0.9612 \\
$\zeta_{d}$ & 0.1835 & 0.1507 \\
$R(\mathrm{~m})$ & 1.0744 & 1.4378 \\
$h(\mathrm{~m})$ & 0.7534 & 4.9640 \\
\hline
\end{tabular}

The critical earthquake record used for the ten-story structure was the 1999 Duzce (BOL090) earthquake. The displacement and total acceleration values of the critical earthquake obtained in the ten-story structure model, as a result of the optimization, are shown in Table 9.

Table 9. TLD plus ten-story building model; critical earthquake analysis results.

\begin{tabular}{cccc}
\hline \multirow{2}{*}{ Algorithm } & \multirow{2}{*}{$\begin{array}{c}\text { Structure } \\
\text { Without TLD }\end{array}$} & \multicolumn{2}{c}{ Structure with TLD } \\
\cline { 3 - 4 } & & HS & AHS \\
\hline Displacement $(\mathrm{m})$ & 0.4101091 & 0.2968907 & 0.2943832 \\
\hline Total Acceleration $\left(\mathrm{m} / \mathrm{s}^{2}\right)$ & 19.283306 & 14.3064378 & 14.0530882 \\
\hline
\end{tabular}

The displacement-time and total acceleration-time graphs obtained from the critical earthquake analysis of the ten-story structure are shown in Figures 10 and 11, respectively, using the the HS and AHS algorithms.
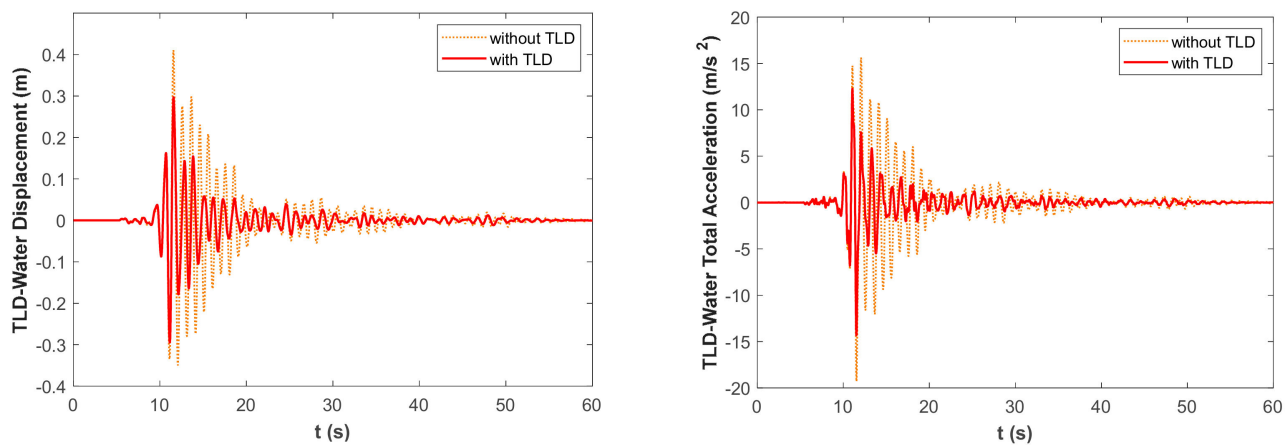

Figure 10. HS optimization, displacement-time, and total acceleration-time graphs of critical seismic analysis in a ten-story structure.
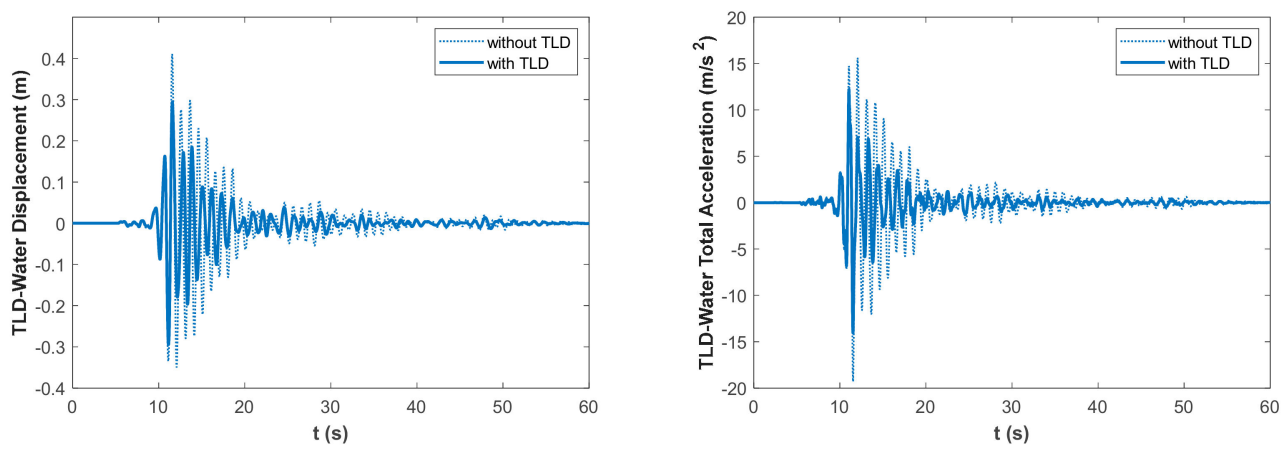

Figure 11. AHS optimization, displacement-time, and total acceleration-time graphs of critical seismic analysis in a ten-story structure. 


\section{Discussion}

In this study, the contribution of adaptive algorithm parameters, in the HS algorithm, to the optimization process, in single and multi-story buildings, in different periods, exposed to earthquake loads, was investigated. Classical HS and adaptively obtained AHS algorithm performances were compared in three different construction periods for a singlestory structure and a ten-story structure. As a single case, AHS was compared with the other two variants of HS. AHS was found to be more effective than IHS and LHS in the reduction of displacement.

Concerning the displacement and total acceleration values obtained as a result of the optimization, the reduction percentages, compared to the structure without a TLD, are shown in Table 10. The mean and standard deviation values of the 10 optimizations are provided in Table 11 for the HS and AHS algorithms.

Table 10. Structure displacement and total acceleration reduction percentages for structures with a TLD.

\begin{tabular}{|c|c|c|c|c|c|c|c|c|}
\hline \multirow{3}{*}{ Variable } & \multicolumn{6}{|c|}{ Single-Storey Structure } & \multirow{2}{*}{\multicolumn{2}{|c|}{ Ten-Storey Structure }} \\
\hline & \multicolumn{2}{|c|}{$\mathrm{T}=0.5 \mathrm{~s}$} & \multicolumn{2}{|c|}{$\mathrm{T}=1.0 \mathrm{~s}$} & \multicolumn{2}{|c|}{$\mathrm{T}=1.5 \mathrm{~s}$} & & \\
\hline & HS & AHS & HS & AHS & HS & AHS & HS & AHS \\
\hline Displacement (m) & $28.23 \%$ & $28.52 \%$ & $13.93 \%$ & $14.87 \%$ & $12.07 \%$ & $12.29 \%$ & $27.61 \%$ & $28.22 \%$ \\
\hline Total Acceleration $\left(\mathrm{m} / \mathrm{s}^{2}\right)$ & $26.97 \%$ & $27.29 \%$ & $15.53 \%$ & $16.15 \%$ & $12.75 \%$ & $12.83 \%$ & $25.81 \%$ & $27.12 \%$ \\
\hline
\end{tabular}

Table 11. Means and standard deviations of ten optimizations of maximum displacement in critical earthquake analysis.

\begin{tabular}{cccccc}
\hline \multirow{2}{*}{ Structure } & & \multicolumn{2}{c}{ HS } & \multicolumn{2}{c}{ AHS } \\
\cline { 3 - 6 } & & Mean (m) & $\begin{array}{c}\text { Standard } \\
\text { Deviation }\end{array}$ & Mean (m) & $\begin{array}{c}\text { Standard } \\
\text { Deviation }\end{array}$ \\
\hline \multirow{3}{*}{$\begin{array}{c}\text { Single-Storey } \\
\text { Structure }\end{array}$} & $\mathrm{T}=0.5 \mathrm{~s}$ & 0.1275797 & 0.0001412 & 0.1268766 & 0.0000020 \\
\cline { 2 - 6 } & $\mathrm{T}=1.0 \mathrm{~s}$ & 0.2473938 & 0.0000460 & 0.2446044 & 0.0000005 \\
\hline \multicolumn{2}{c}{$\mathrm{T}=1.5 \mathrm{~s}$} & 0.2577560 & 0.0001492 & 0.2567763 & 0.0000051 \\
\hline Ten-Storey Structure & 0.2973825 & 0.0001058 & 0.2943965 & 0.0000034 \\
\hline
\end{tabular}

The standard deviations of the maximum displacement values of the critical seismic analysis, obtained as a result of 10 optimizations, were small in both algorithms, and these values were almost zero for the AHS algorithm. While optimum results were obtained from the HS algorithm for the ten-story structure and $0.5 \mathrm{~s}, 1 \mathrm{~s}$, and $1.5 \mathrm{~s}$ in the single-story structure, in 17, 925, 942, and 871 iterations, respectively, in the AHS algorithm, optimum results were obtained in $640,969,995$, and 403 iterations, respectively. In this case, it cannot be said that one is more advantageous than the other in terms of computation time, concerning the HS and AHS algorithms; however, it shall be noted that AHS has lower structural responses. From this, the importance of adapting algorithm parameters for optimum selection is understood.

\section{Conclusions}

The optimization of tuned liquid dampers is important in terms of control performance. Considering the maximum displacement reduction percentages of the critical earthquake analysis obtained from this study, it can be seen that the effect on the control performance increases as the structure period decreases.

In the model where the natural period of the structure was $0.5 \mathrm{~s}$, the maximum displacement reduction of $28.52 \%$ was achieved, while a decrease of $28.22 \%$ was achieved in the ten-story structure. In the light of these data, it is understood that optimizing 
TLD devices, which are generally used in the control of wind vibrations, can show good damping performance in seismic excitations. When the harmony search algorithm and the optimization results of the adaptive harmony search algorithm, obtained by its adaptation, are examined, it can be determined that the AHS algorithm provides better displacement reduction than the classical HS algorithm. Considering the total acceleration values, it is seen that the single-story structure provides a $27.29 \%$ decrease in the $0.5 \mathrm{~s}$ period, and the ten-story structure provides a $27.12 \%$ decrease. It is understood that TLD optimization is very effective in reducing the total acceleration, as well as the displacement. It has been determined that the HMCR and FW values can be very different from the values provided without adjusting the optimum values. Adapting the parameters to include the correct values of these parameters increased damping performance. Considering all these results, it can be said that adapting the algorithm parameters makes the optimization more efficient.

Author Contributions: A.O., G.B. and S.M.N. generated the analysis code. A.O. and S.M.N. developed the theory, background, and formulations of the active control system. The modification of HS was performed by A.O. and G.B. The text of the paper was written by S.M.N., G.B. and A.O. The figures were drawn by S.M.N., G.B. and A.O. S.K. and Z.W.G. edited the paper and supervised the research direction. All authors have read and agreed to the published version of the manuscript.

Funding: This work was supported by the National Research Foundation of Korea (NRF) grant, funded by the Korean government (MSIT) (2020R1A2C1A01011131).

Data Availability Statement: The data of the study can be provided by contacting with the corresponding author.

Conflicts of Interest: The authors declare no conflict of interest.

\section{References}

1. Tanveer, M.; Usman, M.; Khan, I.U.; Farooq, S.H.; Hanif, A. Material optimization of tuned liquid column ball damper (TLCBD) for the vibration control of multi-story structure using various liquid and ball densities. J. Build. Eng. 2020, 32, 101742. [CrossRef]

2. Ocak, A.; Bekdaş, G.; Nigdeli, S.M. A metaheuristic-based optimum tuning approach for tuned liquid dampers for structures. Struct. Des. Tall Spec. Build. 2022, 31, e1907. [CrossRef]

3. Chang, C.C.; Gu, M. Suppression of vortex-excited vibration of tall buildings using tuned liquid dampers. J. Wind Eng. Ind. Aerodyn. 1999, 83, 225-237. [CrossRef]

4. Casciati, F.; De Stefano, A.; Matta, E. Simulating a conical tuned liquid damper. Simul. Model. Pract. Theory 2003, 11, 353-370. [CrossRef]

5. Love, J.S.; Tait, M.J. A preliminary design method for tuned liquid dampers conforming to space restrictions. Eng. Struct. 2012 40, 187-197. [CrossRef]

6. Zhang, Z. Numerical and experimental investigations of the sloshing modal properties of sloped-bottom tuned liquid dampers for structural vibration control. Eng. Struct. 2020, 204, 110042. [CrossRef]

7. Cavalagli, N.; Agresta, A.; Biscarini, C.; Ubertini, F.; Ubertini, S. Enhanced energy dissipation through 3D printed bottom geometry in Tuned Sloshing Dampers. J. Fluids Struct. 2021, 106, 103377. [CrossRef]

8. Fujino, Y.; Sun, L.; Pacheco, B.M.; Chaiseri, P. Tuned liquid damper (TLD) for suppressing horizontal motion of structures. J. Eng. Mech. 1992, 118, 2017-2030. [CrossRef]

9. Sun, L.M.; Fujino, Y.; Pacheco, B.M.; Chaiseri, P. Modelling of tuned liquid damper (TLD). J. Wind. Eng. Ind. Aerodyn. 1992, 43, 1883-1894. [CrossRef]

10. Yu, J.K.; Wakahara, T.; Reed, D.A. A non-linear numerical model of the tuned liquid damper. Earthq. Eng. Struct. Dyn. 1999, 28, 671-686. [CrossRef]

11. Vickery, B.J.; Isyumov, N.; Davenport, A.G. The role of dumping, mass, and acceleration. J. Wind Eng. Ind. Aerodyn. 1983, 11, 285-294. [CrossRef]

12. Rana, R.; Soong, T.T. Parametric study and simplified design of tuned mass dampers. Eng. Struct. 1998, 20, 193-204. [CrossRef]

13. Geem, Z.W.; Kim, J.H.; Loganathan, G.V. A new heuristic optimization algorithm: Harmony search. Simulation 2001, 76, 60-68. [CrossRef]

14. Koziel, S.; Yang, X.S. Computational Optimization, Methods, and Algorithms; Springer: Berlin/Heidelberg, Germany, 2011; Volume 356, pp. 1-11.

15. Nigdeli, S.M.; Bekdas, G.; Kim, S.; Geem, Z.W. A novel harmony search based optimization of reinforced concrete biaxially loaded columns. Struct. Eng. Mech. 2015, 54, 1097-1109. [CrossRef]

16. Siddique, N.; Adeli, H. Applications of harmony search algorithms in engineering. Int. J. Artif. Intell. Tools 2015, $24,1530002$. [CrossRef] 
17. De Almeida, F.S. Optimization of laminated composite structures using harmony search algorithm. Compos. Struct. 2019, 221, 110852. [CrossRef]

18. Cakiroglu, C.; Bekdaş, G.; Kim, S.; Geem, Z.W. Optimisation of Shear and Lateral-Torsional Buckling of Steel Plate Girders Using Meta-Heuristic Algorithms. Appl. Sci. 2020, 10, 3639. [CrossRef]

19. Cakiroglu, C.; Islam, K.; Bekdaş, G.; Kim, S.; Geem, Z.W. Metaheuristic Optimization of Laminated Composite Plates with Cut-Outs. Coatings 2021, 11, 1235. [CrossRef]

20. Arama, Z.A.; Kayabekir, A.E.; Bekdaş, G.; Kim, S.; Geem, Z.W. The Usage of the Harmony Search Algorithm for the Optimal Design Problem of Reinforced Concrete Retaining Walls. Appl. Sci. 2021, 11, 1343. [CrossRef]

21. Ulusoy, S.; Bekdaş, G.; Nigdeli, S.M.; Kim, S.; Geem, Z.W. Performance of optimum tuned PID controller with different feedback strategies on active-controlled structures. Appl. Sci. 2021, 11, 1682. [CrossRef]

22. Nigdeli, S.M.; Bekdaş, G. Optimum tuned mass damper design in frequency domain for structures. KSCE J. Civ. Eng. 2017, 21, 912-922. [CrossRef]

23. Jin, C.; Chung, W.C.; Kwon, D.S.; Kim, M. Optimization of tuned mass damper for seismic control of submerged floating tunnel. Eng. Struct. 2021, 241, 112460. [CrossRef]

24. Zhang, H.Y.; Zhang, L.J. Tuned mass damper system of high-rise intake towers optimized by improved harmony search algorithm Eng. Struct. 2017, 138, 270-282. [CrossRef]

25. Den Hartog, J.P. Mechanical Vibrations, 3rd ed.; McGraw-Hill: New York, NY, USA, 1947; ISBN 978-1443725361.

26. Warburton, G.B. Optimum absorber parameters for various combinations of response and excitation parameters. Earthq. Eng. Struct. Dyn. 1982, 10, 381-401. [CrossRef]

27. Sadek, F.; Mohraz, B.; Taylor, A.W.; Chung, R.M. A method of estimating the parameters of tuned mass dampers for seismic applications. Earthq. Eng. Struct. Dyn. 1997, 26, 617-635. [CrossRef]

28. Leung, A.Y.T.; Zhang, H. Particle swarm optimization of tuned mass dampers. Eng. Struct. 2009, 31, 715-728. [CrossRef]

29. Keshtegar, B.; Etedali, S. Nonlinear mathematical modeling and optimum design of tuned mass dampers using adaptive dynamic harmony search algorithm. Struct. Control. Health Monit. 2018, 25, e2163. [CrossRef]

30. Alkhadashi, A.; Mohammad, F.; Zubayr, R.O.; Klalib, H.A.; Balik, P. Multi-objective design optimization of steel-framed structures using three different methods. Int. J. Struct. Integr. 2021, 13, 92-111. [CrossRef]

31. Toklu, Y.C.; Bekdaş, G.; Yücel, M.; Nigdeli, S.M.; Kayabekir, A.E.; Kim, S.; Geem, Z.W. Total Potential Optimization Using Metaheuristic Algorithms for Solving Nonlinear Plane Strain Systems. Appl. Sci. 2021, 11, 3220. [CrossRef]

32. Keshtegar, B.; Nehdi, M.L.; Kolahchi, R.; Trung, N.T.; Bagheri, M. Novel hybrid machine learning model for predicting the shear strength of reinforced concrete shear walls. Eng. Comput. 2021, 1-12. [CrossRef]

33. Peifeng, W.; Liqun, G.; Xiang, Z.; Dongli, Z. Application of adaptive harmony search algorithm in Structural engineering design Chin. J. Sci. Instrum. 2012, 33, 1676-1680.

34. Federal Emergency Management Agency. Quantification of Building Seismic Performance Factors; FEMA P-695; Federal Emergency Management Agency: Washington, DC, USA, 2009.

35. MathWorks. Matlab; R2018a; MathWorks: Natick, MA, USA, 2018.

36. Sharma, V.; Arun, C.O.; Krishna, I.P. Development and validation of a simple two degree of freedom model for predicting maximum fundamental sloshing mode wave height in a cylindrical tank. J. Sound Vib. 2019, 461, 114906. [CrossRef]

37. Bauer, H.F. Tables and graphs of zeros of cross product bessel functions. Math. Comput. 1964, 18, 128.

38. Ibrahim, R.A. Liquid Sloshing Dynamics: Theory and Applications; Cambridge University Press: Cambridge, UK, 2005; ISBN 0-521-83885-1.

39. Abramson, H.N. The Dynamic Behavior of Liquids in Moving Containers, with Applications to Space Vehicle Technology; National Aerospace Space Administration (NASA): Washington, DC, USA, 1966.

40. Mikishev, G.N.; Dorozhkin, N.Y. An experimental investigation of free oscillations of a liquid in containers. Izv. Akad. Nauk SSSR Otd. Tekhnicheskikh Nauk Mekhanika Mashinostr. 1961, 4, 48-53.

41. Ouyang, H.B.; Gao, L.Q.; Li, S.; Kong, X.Y.; Wang, Q.; Zou, D.X. Improved harmony search algorithm: LHS. Appl. Soft Comput. 2017, 53, 133-167. [CrossRef]

42. Singh, M.P.; Matheu, E.E.; Suarez, L.E. Active and semi-active control of structures under seismic excitation. Earthq. Eng. Struct. Dyn. 1997, 26, 193-213. [CrossRef] 